\title{
THE IMPACT OF VIRTUAL REALITY SIMULATION ON COGNITIVE ACHIEVEMENT OF NURSING STUDENTS
}

\author{
Ryan Hara Permana ${ }^{1 *}$, Mira Suryani ${ }^{2}$, Erick Paulus ${ }^{3}$, Windy Rakhmawati ${ }^{4}$ \\ ${ }^{1,4}$ Faculty of Nursing, Universitas Universitas Padjadjaran \\ ${ }^{2,3}$ Faculty of Mathematics and Natural Sciences, Universitas Padjadjaran \\ Email*: ryan.hara@unpad.ac.id
}

\begin{abstract}
Introduction: Simulation of nursing care in patients with acute respiratory infections (ARI) requires a method that is high fidelity. This study aims to determine the impact of Virtual Reality Simulation (VRS), as a learning method, on the improvement of cognitive abilities of undergraduate nursing students in conducting nursing care of the ARI case. Methods: This study used a quasi-experimental design with pre and post-test on the control and intervention group. The sampling technique used purposive sampling, with a total of 27 respondents divided into nine respondents in each group, including the control group (group A) intervention group (Group B and $C$ ). There were three different methods in the implementation of VRS as learning activities. Data were analyzed by ANCOVA test. Results: The results showed a significant impact on the application of VRS as a learning method with $p<0.05$ (0.025). Conclusion: This significant impact was obtained in the implementation of VRS as a stand-alone learning method.
\end{abstract}

Keywords: Cognitive Ability; Learning Methods; Nursing Education; Virtual Reality Simulation

\section{INTRODUCTION}

The competence of nursing care for patients with Acute Respiratory Infections (ARI) is essential for professional nurses. Globally, ARI is the second most common cause of morbidity and mortality in children under five. ARI is considered as the leading cause of mortality in infants and toddlers in developing countries. In 2015, infant mortality caused by ARI reached around one million people or about $16 \%$ of total deaths in the world (WHO, 2015). ARI is also one of the leading causes of patient visits in Primary Health Care (40\% -60\%) and hospitals (15\% $30 \%$ ) in Indonesia (Kemenkes RI, 2015). Therefore, nurses' ability to caring for ARI patients is expected to contribute to the level of children's health in Indonesia.

The use of Virtual Reality Simulation (VRS) is expected to be able to address the limitations of learning methods, especially in nursing education to provide learning methods a more efficient method and also facilitate a high fidelity, and safe learning environments, and support experiential learning (Wan, Ho and Lam, 2019). The VRS has been developed since 2018 by the Virtual Reality Simulation research team at the university is a smartphone-based VR program combined with VR gear to display threedimensional visuals and stereo. They were making it possible to be accessed anywhere and anytime. In this virtual clinical environment, users can interact with patients textually and practice nursing care to ARI patients. The selfassessment feature allows students to do selflearning with immediate feedback (Almousa et al., 2019; Andersen et al., 2019).

The VRS scenario at this stage aims to train the ability of nursing students to provide nursing care to ARI patients. So, this study aimed to investigate the ability of VRS in improving nursing students' cognitive abilities regarding the concepts and theories of nursing care, analysis of nursing problems, and nursing intervention procedures, specifically in the ARI case.

\section{METHODS}


A quasi-experimental study applied a pre and post-test design with a control group. This research is the second out of three stages of research and development, which aims to develop a Virtual Reality Simulation (VRS) for nursing education (Permana et al., 2018). Based on the VRS development cycle, according to AgileScrum (Larman, 2004), this research focuses on the pilot phase.

The study was conducted in August 2019 at the Faculty of Nursing. The sampling technique used purposive sampling, with only the respondents who met the criteria included in this study. The inclusion criteria in this study were the undergraduate nursing students in the Faculty of Nursing, who had passed the Basic Concepts of Nursing and Basic Nursing Sciences, had never attended a child nursing course. The exclusion criteria were students who have learned about nursing care in patients with ARI. The number of samples is calculated by the rule of thumb, which is $5-10$ times the number of variables. The total number of respondents was 27 respondents. The dense schedule of study and the limitations of research logistics has limited the number of respondents.

The respondents were divided into three groups randomly, namely group A which was the control group, and groups $\mathrm{B}$ and $\mathrm{C}$ as the intervention groups. The evaluation of cognitive abilities was conducted by pre and post-test methods using a questionnaire developed by the research team. The instrument consisted of 15 questions with choices of $\mathrm{A}, \mathrm{B}, \mathrm{C}$, and $\mathrm{D}$, and the score range was 0-100. Before using the application, all groups were asked to do a pre-test. Then, intervention is treated based on a different group, where the control group got a 60-minutes lecture about ARI, while the intervention group got a VRS session for about 17-minutes. At the end of the intervention, a post-test was conducted for all groups. Diagram 1 shows the flow of data collection procedures according to the group.

Diagram 1. The flow of data collection

Group A (Control):

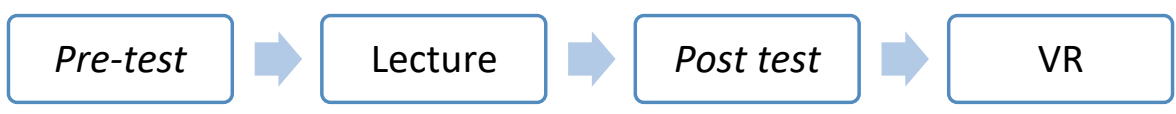

Group B (Intervention group 1):

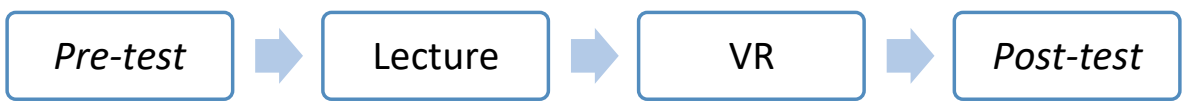

Group C (Intervention group 2):
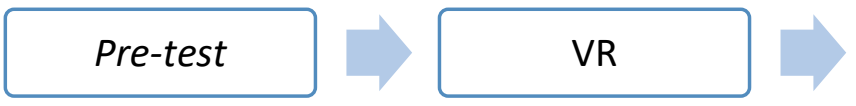

Post-test
Participation was voluntary, and this research had small risks of physical injury as there was no invasive procedure. The confidentiality of the data is protected with anonymity.
The data gained from the evaluation of the use of Virtual Reality Simulation (VRS) on the cognitive abilities of nursing students were analyzed by the analysis of covariance (ANCOVA) test using computer software. The 
ANCOVA was used to test the main effects and interactions of categorical variables on continuous dependent variables, controlling for the effects of other selected continuous variables.
The article has been following for ethical consideration. The manuscript has been considering justice, anonymity, beneficence and non-maleficence. The researched has been conducted by respondents approval.

\section{RESULTS}

Figure 1. Feature questions and feedback on VRS

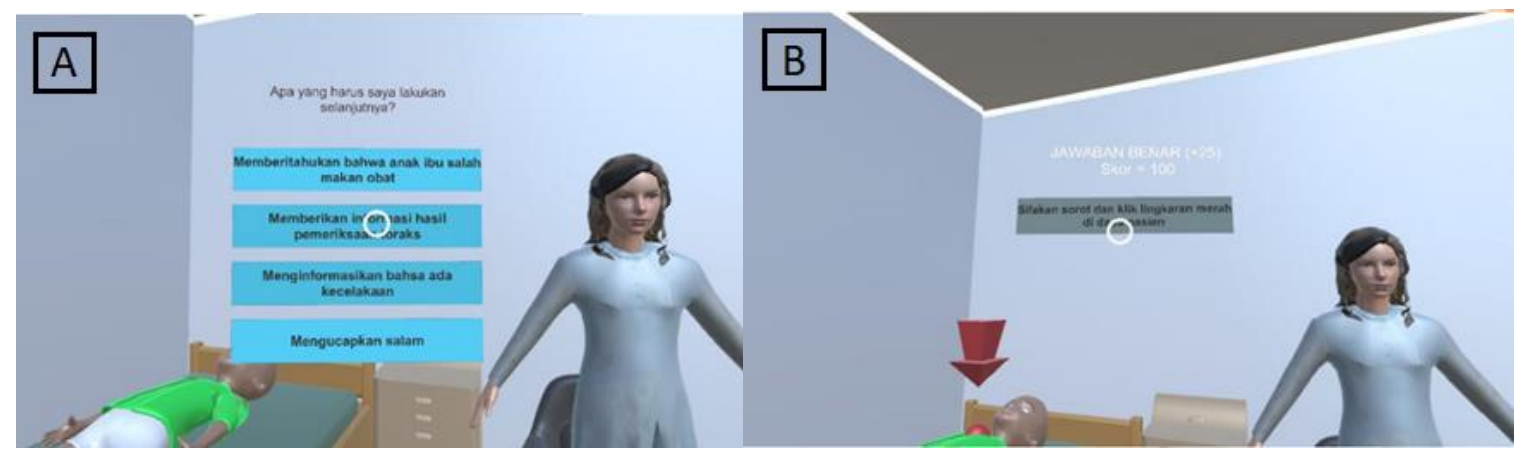

Note A) Example of self-assessment on VRS; B) Example of input in the form of a score on the correct answer.

Figure 1 shows the example of the VRS that tested to the participants. There was a selfassessment feature in the VRS that gave feedback to the user according to their answer. The feedback delivered in the form of a score on the correct answer and the opportunity to select another answer if the first answer is wrong.

Table 1. Frequency distribution of research respondents $(n=27)$

\begin{tabular}{|c|c|c|c|}
\hline No & Item & Frequency & Percentage (\%) \\
\hline \multirow[t]{3}{*}{1} & Sex & & \\
\hline & Male & 1 & 3.70 \\
\hline & Female & 26 & 96.30 \\
\hline \multirow[t]{4}{*}{2} & Age & & \\
\hline & 22 & 19 & 70.37 \\
\hline & 23 & 4 & 14.81 \\
\hline & 24 & 4 & 14.81 \\
\hline \multirow[t]{4}{*}{3} & Semester & & \\
\hline & 2 & 19 & 70.37 \\
\hline & 4 & 4 & 14.81 \\
\hline & 6 & 4 & 14.81 \\
\hline
\end{tabular}

Table 1 shows that most respondents were female $(96.30 \%)$ with a majority age of 22 years $(70.37 \%)$, and the majority are in the second semester. The data normality test results 
Jurnal INJEC Vol. 4 No. 2 December 2019: 147-152

with Shapiro-Wilk showed that the data were normally distributed with $\mathrm{p}>0.05$ (0.318 and 0.69) (Table 2).

Table 2. Data Normality Test Results $(n=27)$

\begin{tabular}{lcccccc}
\hline & \multicolumn{3}{c}{ Kolmogorov-Smirnov $^{a}$} & \multicolumn{3}{c}{ Shapiro-Wilk } \\
\cline { 2 - 7 } & Statistic & $d f$ & Sig. & Statistic & $d f$ & Sig. \\
\hline Post-test & .231 & 27 & .001 & .930 & 27 & .069 \\
Pre-test & .172 & 27 & .039 & .957 & 27 & .318 \\
\hline
\end{tabular}

a. Lilliefors Significance Correction

Table 3. Results of Descriptive Statistics of Analysis of Pre and Post Test Mean Values (n=27)

Dependent Variable: PostTest

\begin{tabular}{lccc}
\hline Group & Mean & Std. Deviation & $N$ \\
A & 66.66 & 7.45 & 9 \\
B & 54.07 & 18.39 & 9 \\
C & 68.89 & 7.45 & 9 \\
Total & 63.21 & 13.50 & 27 \\
\hline
\end{tabular}

The highest mean score was in group $\mathrm{C}$ (68.89), where respondents only got a VRS session as the intervention without any lecture.
While the lowest standard deviation was in groups A and C (7.45) (Table 3).

Table 4. ANCOVA Test Results

\begin{tabular}{lcccccc}
\hline $\begin{array}{l}\text { Type III Sum } \\
\text { of Squares }\end{array}$ & $d f$ & $\begin{array}{c}\text { Mean } \\
\text { Square }\end{array}$ & $F$ & Sig. & $\begin{array}{c}\text { Partial Eta } \\
\text { Squared }\end{array}$ \\
$\begin{array}{l}\text { Corrected } \\
\text { Model }\end{array}$ & $1327.55^{\mathrm{a}}$ & 3 & 442.518 & 2.979 & .052 & .280 \\
Intercept & 2247.77 & 1 & 2247.778 & 15.130 & .001 & .397
\end{tabular}


The Impact of Virtual Reality Simulation ... (Ryan, et.al)

$\begin{array}{lcccccr}\text { Pretest } & 178.34 & 1 & 178.348 & 1.200 & .285 & .050 \\ \text { Group } & 1294.86 & 2 & 647.430 & 4.358 & .025 & .275 \\ \text { Error } & 3417.02 & 23 & 148.566 & & \\ \text { Total } & 112626.97 & 27 & & & \\ \text { Corrected } & 4744.57 & 26 & & & \\ \text { Total } & & & & & \end{array}$

a. $R$ Squared $=.280($ Adjusted $R$ Squared $=.186)$

From Table 4, it is known that there are statistically significant differences in the mean of pre and post-test scores between groups with $\mathrm{p}$ $<0.05(0.025)$.

\section{DISCUSSIONS}

Statistically, VRS has a significant influence on improving the cognitive abilities of nursing students in practicing nursing care in the case of patients with ARI, compared to the conventional method, namely face-to-face lectures. Research by Dubovi, Levy, and Dagan (2017) about Pharmacology Inter-Leaved Learning Virtual Reality (PILL-VR) showed that practicing medication administration with VR combined with lectures can provide a better achievement, more persistent and comprehensive, compared to the lecture method only. VR technology is also considered to have the potential to provide access to affordable and flexible learning in higher education and is crucial for developing student skills (Bahreman and Swoboda, 2016; Dubovi, Levy and Dagan, 2017).

The highest average score in group $\mathrm{C}$ indicates that the VRS can stand alone as a learning method, explicitly to teach concepts and theories of nursing care, the skills of nursing problem analysis, and nursing intervention procedures. According to Cook et al. (2011), many kinds of literature states that simulation technology has a significant effect on improving learning outcomes, including knowledge, skills, and attitudes. However, research on the implementation of VR in the field of nursing education is still sparse, and its application currently covers limited areas of nursing practice, including hospitals, long-term residential care, and education areas.

The VRS improved respondents' cognitive abilities that influenced by the selfassessment feature. VRS is equipped with a series of questions that are supplemented by quantitative feedback in the form of scores (Figure 1) (Permana et al., 2018). With the selfassessment features and VRS applications that can be accessed through the Android app provides flexibility in learning so that it allows users to learn self-learning. Students can construct knowledge independently through a repetitive learning process with VRS. According to Andersen et al. (2019), simulations with VR technology with self-assessment features can improve clinical skills performance in a safe environment and accelerate the learning curve to reduce the time needed to learn. Qualitative feedback features in the form of detailed explanations of each answer option, both right and wrong answers, need to be considered for further VRS development, to enhance VRS's ability to facilitate independent learning and assist users in shaping reasoning abilities (de 
Souza Silveiraa and Cogob, 2017; Ferguson et al., 2017; Register et al., 2020).

\section{CONCLUSIONS}

The Virtual Reality Simulation (VRS) has a significant influence in improving the cognitive abilities of nursing students in practicing nursing care in the case of patients with ARI, compared to conventional methods, namely face-to-face lectures. VRS can stand alone as a learning method explicitly to teach concepts and theories of nursing care, the skills of nursing problem analysis, and nursing intervention procedures. The limited number of samples became a weakness in this study.

\section{ACKNOWLEDGEMENT}

This research was fully funded by the AINEC RESEARCH AWARDS Grant 2019. We are grateful to our colleagues from the Faculty of Mathematics and Natural Sciences, Universitas Padjadjaran, who provided insight and support for the development of VRS, which greatly assisted this research.

\section{REFERENCES}

Almousa, O. et al. (2019) 'Virtual Reality Simulation Technology for Cardiopulmonary Resuscitation Training: An Innovative Hybrid System With Haptic Feedback', Simulation and Gaming, 50(1), pp. 6-22. doi: $10.1177 / 1046878118820905$.

Andersen, S. A. W. et al. (2019) 'The effect of structured self-assessment in virtual reality simulation training of mastoidectomy', European Archives of Oto-Rhino-Laryngology. Springer Berlin Heidelberg, 276(12), pp. 3345-3352. doi: 10.1007/s00405-019-05648-6.

Bahreman, N. T. and Swoboda, S. M. (2016) 'Honoring diversity: developing culturally competent communication skills through simulation', Journal of Nursing Education. Slack Incorporated, 55(2), pp. 105-108.
Cook, D. A. et al. (2011) 'Technology-enhanced simulation for health professions education: a systematic review and metaanalysis', Jama. American Medical Association, 306(9), pp. 978-988.

Dubovi, I., Levy, S. T. and Dagan, E. (2017) 'Now I know how! The learning process of medication administration among nursing students with non-immersive desktop virtual reality simulation', Computers \& Education. Elsevier, 113, pp. 16-27.

Ferguson, C. et al. (2017) 'The integration and evaluation of a social-media facilitated journal club to enhance the student learning experience of evidence-based practice: A case study.', Nurse Education Today. Graduate School of Health, University of Technology Sydney, Australia: Elsevier B.V., 48, pp. 123128. doi: 10.1016/j.nedt.2016.10.002.

Kemenkes RI (2015) 'Manajemen Terpadu Balita Sakit (MTBS)', Jakarta: Modul, pp. 1-7.

Larman, C. (2004) Agile and iterative development: a manager's guide. Addison-Wesley Professional.

Permana, R. H. et al. (2018) 'The Storyboard Development of Virtual Reality Simulation (VRS) of Patient with Respiratory System Disturbance', in Proceeding of International Nursing Conference 2018. AIPNI.

Register, S. J. et al. (2020) 'Using AIDET ${ }^{\circledR}$ Education Simulations to Improve Patient Experience Scores', Clinical Simulation in Nursing. Elsevier, 38, pp. 14-17.

De Souza Silveiraa, M. and Cogob, A. L. P. (2017) 'The contributions of digital technologies in the teaching of nursing skills: an integrative review', Rev Gaúcha Enferm, 38(2), p. e66204.

Wan, W. H., Ho, A. and Lam, Y. (2019) 'The Effectiveness of Virtual Reality-Based Simulation in Health Professions Education Relating to Mental Illness : A Literature Review', pp. 646-660. doi: 10.4236/health.2019.116054.

WHO (2015) 'World health statistics 2015'. World Health Organization 